\title{
Novel Methods in Multiple Criteria Decision-Making Process (MCRAT and RAPS)-Application in the Mining Industry
}

\author{
Katarina Urošević *, Zoran Gligorić $\mathbb{( D}$, Igor Miljanović $\mathbb{D}$, Čedomir Beljić $\mathbb{(}$ and Miloš Gligorić \\ Faculty of Mining and Geology, University of Belgrade, Đušina 7, 11000 Belgrade, Serbia; \\ zoran.gligoric@rgf.bg.ac.rs (Z.G.); igor.miljanovic@rgf.bg.ac.rs (I.M.); cedomir.beljic@rgf.bg.ac.rs (Č.B.); \\ milos.gligoric@rgf.bg.ac.rs (M.G.) \\ * Correspondence: katarina.urosevic@rgf.bg.ac.rs
}

check for

updates

Citation: Urošević, K.; Gligorić, Z.; Miljanović, I.; Beljić, Č.; Gligorić, M. Novel Methods in Multiple Criteria Decision-Making Process (MCRAT and RAPS)-Application in the Mining Industry. Mathematics 2021, 9, 1980. https://doi.org/ $10.3390 /$ math 9161980

Academic Editors: Víctor Yepes and José Moreno-Jiménez

Received: 2 July 2021

Accepted: 13 August 2021

Published: 19 August 2021

Publisher's Note: MDPI stays neutral with regard to jurisdictional claims in published maps and institutional affiliations.

Copyright: (c) 2021 by the authors. Licensee MDPI, Basel, Switzerland. This article is an open access article distributed under the terms and conditions of the Creative Commons Attribution (CC BY) license (https:// creativecommons.org/licenses/by/ $4.0 /)$.

\begin{abstract}
Multiple criteria decision making (MCDM) is a supporting tool which is widely spread in different areas of science and industry. Many researchers have confirmed that MCDM methods can be useful for selecting the best solution in many different problems. In this paper, two novel methods are presented and applied on existing decision-making processes in the mining industry. The first method is multiple criteria ranking by alternative trace (MCRAT) and the second is ranking alternatives by perimeter similarity (RAPS). These two novel methods are demonstrated in decisionmaking problems and compared with the ranking of the same alternatives by other MCDM methods. The mining process often includes drilling and blasting operations as the most common activities for exploitation of raw materials. For optimal blasting design it is important to select the most suitable parameters for the blasting pattern and respect characteristics of the working environment and production conditions. By applying novel methods, how to successfully select the most proper blasting pattern respecting all conditions that must be satisfied for economic aspects and the safety of employees and the environment is presented.
\end{abstract}

Keywords: multiple criteria decision making; novel methods; mining industry; blasting pattern

\section{Introduction \\ 1.1. Multiple Criteria Decision Making Methods}

A group of multiple criteria (or multicriteria) decision-making (MCDM) methods (sometimes referred to as techniques) is widely considered to be one of the most important and often used support tools for decision-making processes in business and engineering, across a wide area of human interaction with natural and man-made subjects [1-4]. Typically, the methods deal with multiple conflicting evaluation criteria to select a single alternative or rank the alternative solutions to a decision-making problem.

Multiple criteria decision making is now a well-established, defined and comprehensively studied branch of operations research. Historically, the advent of MCDM coincided with the onset of wider usage of operations research tools and methods. While the core ideas exemplified by the multiple criteria methods can be traced back to the 18th century, if not earlier [5], the methods widely used now, such as ELECTRE (1965) [6], AHP (1977) [7], TOPSIS (1980) [8] and PROMETHEE (1986) [9] were clearly first developed in the latter half of the 20th century as well as numerous others from the same group [10-12].

An abundance of literature exists in relation to the scientific background of MCDM methods, including the discussion on their distinction, classification or their expected scope of use, and even more is written every day, in particular concerning the case studies of their usage in a professional environment [13]. State of the art trends in MCDM during the previous decade reveal at least two clear threads: a tendency toward compartmentalization, i.e., providing the background for using the particular methods in particular settings, and the hybridization of well-known and other methods, with the inclusion of fuzzy or rough sets or the gray relational model approach [14]. 
In many observed case studies, the recurring issue, directly related to the vast number (estimated to be higher than one hundred) of different MCDM methods, regards selecting the appropriate MCDM method to use. According to Wang et al. there are no better or worse methods, only methods that fit better to a certain situation. Furthermore, the authors state that there are three main disadvantages to the use of MCDM methods: different results when using the same method, different methods yielding different results and the fact that evaluation or comparison of MCDM methods is a complex issue [15]. In these settings, it is not unusual to adopt and adapt an existing method or even develop a new one for the case in question.

The development of novel methods in MCDM does not seem to be a predominant research direction nowadays. According to Alinezhad and Khalili [16], only a handful of methods developed in the last two decades are readily used in the business or engineering environment, for example MOORA (2006) [17] and WASPAS (2012) [18]. The reasons for this situation may stem from different sources, but these can be classified as coming from the overload of methods in use, the insufficient distribution of information regarding novel methods or simply from the timeframe necessary for a novel method to be widely adopted and used.

As the area of their use is expanding, MCDM methods deemed to be quite different in their approach are used in a similar context. Thus, a thorough review on the usability of methods in different settings and their advantages and disadvantages may be in order, alongside a detailed cross-section of the areas of use. In this paper, we present a short assessment of some of the methods used today (Table 1). The assessment is compiled from the authors in [19-23] and amended by selected methods TAOV [24] ARAS [25], and [26] and GRA $[15,27,28]$.

Table 1. Short assessment of various methods used in MCDM.

\begin{tabular}{|c|c|c|c|}
\hline Method & Advantages & Disadvantages & Year of Introduction \\
\hline ELECTRE & $\begin{array}{l}\text { - Takes uncertainty and vagueness } \\
\text { into account. } \\
\text { - } \quad \text { No need for independence of } \\
\text { attributes. } \\
\text { - Very poor performance on a single } \\
\text { criterion may eliminate an } \\
\text { alternative from consideration. }\end{array}$ & $\begin{array}{l}\text { - } \quad \text { Relatively complex algorithm. } \\
\text { A complete ranking of the } \\
\text { alternatives may not be achieved. }\end{array}$ & 1966 \\
\hline SAW & $\begin{array}{l}\text { Intuitive method with simple } \\
\text { algorithm. } \\
\text { Able to compensate between } \\
\text { variables. } \\
\text { - Suitable for the evaluation of a } \\
\text { single alternative. }\end{array}$ & $\begin{array}{l}\text { - Converting minimizing criteria to } \\
\text { maximizing is necessary. } \\
\text { Holds potential for unfounded } \\
\text { results. } \\
\text { - Values should be positive. }\end{array}$ & 1968 \\
\hline AHP & $\begin{array}{l}\text { - } \quad \text { Easy to use. } \\
\text { - } \quad \text { Not data intensive. } \\
\text { Hierarchy structure can easily } \\
\text { adjust to fit many sized problems. } \\
\text { - Improved focus on each criterion } \\
\text { used in the calculations. }\end{array}$ & $\begin{array}{l}\text { - } \quad \text { Possibility for intransitive preferences. } \\
\text { High number of pairwise } \\
\text { comparisons required for large scale } \\
\text { problems. } \\
\text { - } \quad \text { Potential for inconsistencies. } \\
\text { Rank reversal. }\end{array}$ & 1980 \\
\hline VIKOR & $\begin{array}{l}\text { Usable for problems with } \\
\text { difficulties in expressing } \\
\text { preferences. } \\
\text { - Stability analysis included. }\end{array}$ & $\begin{array}{l}\text { - Quantitative information is necessary. } \\
\text { - } \quad \text { Theeds initial weights. } \\
\text { with different values of variables' } \\
\text { weights. }\end{array}$ & 1980 \\
\hline
\end{tabular}


Table 1. Cont.

\begin{tabular}{|c|c|c|c|}
\hline Method & Advantages & Disadvantages & Year of Introduction \\
\hline TOPSIS & $\begin{array}{l}\text { Works with a fundamental } \\
\text { ranking. } \\
\text { - Complete use of allocated } \\
\text { information. } \\
\text { - Simple computation process. }\end{array}$ & $\begin{array}{l}\text { - Not considering correlation of } \\
\text { attributes. } \\
\text { - A strong deviation of an indicator } \\
\text { from the ideal solution strongly } \\
\text { influences the results. } \\
\text { - Suitable when the indicators of } \\
\text { alternatives do not vary very strongly. }\end{array}$ & 1981 \\
\hline PROMETHEE & $\begin{array}{l}\text { Useful with alternatives that are } \\
\text { difficult to harmonize. } \\
\text { Using both qualitative and } \\
\text { quantitative information. } \\
\text { Potential for inclusion of } \\
\text { uncertain and fuzzy data. }\end{array}$ & $\begin{array}{l}\text { - No clear method for assigning criteria } \\
\text { weights. } \\
\text { Moderately complex computation } \\
\text { process. }\end{array}$ & 1986 \\
\hline GRA & $\begin{array}{l}\text { - Providing more distinction in } \\
\text { alternatives ranking. } \\
\text { Suitable for solving problems with } \\
\text { complicated interrelationships } \\
\text { between multiple factors and } \\
\text { variables. }\end{array}$ & $\begin{array}{l}\text { - } \quad \text { Relatively complex procedure. } \\
\text { Relatively high sensitivity to criteria } \\
\text { weights. }\end{array}$ & 1994 \\
\hline MOORA & $\begin{array}{l}\text { - } \quad \text { Relatively simple procedure. } \\
\text { - } \quad \text { Attributes are independent. } \\
\text { Robust method. }\end{array}$ & $\begin{array}{l}\text { The qualitative attributes are } \\
\text { converted into the quantitative } \\
\text { attributes. } \\
\text { Relatively complex calculations } \\
\text { process. }\end{array}$ & 2006 \\
\hline COPRAS & $\begin{array}{l}\text { - Suitable for the evaluation of a } \\
\text { single alternative. } \\
\text { - } \quad \text { Robust method. } \\
\text { - Not requiring minimization of } \\
\text { criteria. }\end{array}$ & $\begin{array}{l}\text { Less stable in data variation case in } \\
\text { comparison to some other methods. } \\
\text { - Sensitive to slight variations in data. }\end{array}$ & 2007 \\
\hline ARAS & $\begin{array}{l}\text { The utility degree is considered as } \\
\text { the ranking of alternatives. } \\
\text { - Attributes are independent. }\end{array}$ & $\begin{array}{l}\text { - The qualitative attributes should be } \\
\text { converted into the quantitative } \\
\text { attributes. }\end{array}$ & 2010 \\
\hline WASPAS & $\begin{array}{l}\text { - } \quad \text { Relatively simple calculation. } \\
\text { The method weighs the beneficial } \\
\text { and non-beneficial criteria in the } \\
\text { problem separately. } \\
\text { The method is useful for the } \\
\text { complete ranking of alternatives. }\end{array}$ & $\begin{array}{l}\text { Taking into consideration only } \\
\text { minimum (for non-beneficial } \\
\text { attributes) and maximum (for } \\
\text { beneficial attributes) values. } \\
\text { Does not consider all the performance } \\
\text { values. }\end{array}$ & 2012 \\
\hline TAOV & $\begin{array}{l}\text { - } \quad \text { Relatively simple procedure. } \\
\text { - Proposes a procedure to guarantee } \\
\text { the independence of the criteria. } \\
\text { No limitations regarding the scale } \\
\text { of criteria. }\end{array}$ & $\begin{array}{l}\text { - Low applicability to conflict } \\
\text { resolution. }\end{array}$ & 2018 \\
\hline
\end{tabular}

MCDM methods have been extensively used in mining engineering and mineral processing. A comprehensive review on this issue has been presented by Sitorus et al. [4]. According to Sitorus et al. decision makers in the mining and mineral processing industry often face complex problems where solving them involves multidisciplinary knowledge including technical, economic, environmental and social aspects, as well as politics and 
regulations [29]. Furthermore, the trend of use of MCDM methods in mining and mineral processing, both individual and hybrid methods, has increased over the last fifteen years, but without the implementation of new or novel methods.

In this paper, two methods designed for the problem of ranking alternatives are presented. Both methods are two-staged, involving, in the first stage, the normalization, weighting and determining a "magnitude" of a component upon obtaining an optimal alternative and the decomposition of alternatives. In the second stage, the first method uses a trace of a matrix (multiple criteria ranking by alternative trace-MCRAT), while the second (ranking the alternatives by perimeter similarity-RAPS) uses the concept of perimeter similarity to determine the ranking of the alternatives.

The two novel methods were validated by comparing the results with the results ob-tained by seven well-known MCDM methods: TAOV [24], ARAS [30], SAW [31], TOPSIS [8], COPRAS [32], VIKOR [33], WASPAS [18] and ELECTRE [6]. The criteria for selecting these were the frequency of use in professional literature and/or similarity of the concept to the pro-posed methods. An evaluation of both methods by means of evaluation criteria proposed by Saaty and Ergu [34] is provided in order to help the reader determine the potential scope of both methods.

\subsection{Drilling and Blasting Problem}

The mining process is a global industry that is of great importance for almost every product we use. Mining projects include many activities that need to be conducted to obtain a final product. Two of these activities are drilling and blasting. These two operations are inseparable, and their role is to separate rock from massive or secondary crushing of rocks.

When drilling and blasting are organized properly, the efficiency of the exploitation process increases and it leads to a reduction of production costs of these operations, which affect the overall production costs of the mine by about $25 \%$ to $40 \%$ [35].

Many researchers have successfully investigated the possibilities of the application of MCDM methods for different drilling and blasting issues and have shown how to optimize parameters or to predict effects of negative consequences of this process, or how to lower the cost of it. Monjezi et al. [36] applied the TOPSIS method to select the most appropriate pattern for limestone. Javad Rahimel et al. [37] also used MCDM methods for selection of the optimal blasting pattern for one iron ore mine. They used AHP for determining the importance of criteria and after that they applied PROMETHEE and TOPSIS for ranking of alternatives. In both studies the result was the successful selection of an optimal blasting design.

The main aim of blasting in the mining process is to accomplish convenient fragmentation of rock which means a suitable size distribution of the rock that can be successfully loaded, transported and milled [38] while at the same time minimize negative effects which can be dangerous for people and the environment. Researchers have conducted many studies about these unfavorable effects such as fly rock, air shock and ground vibrations [39-41].

The third important aim of every mining operation, or in this case blasting, are costs. Bad fragmentation or a higher impact on the environment due to blasting operations leads to additional costs and that is certainly what experts do not want to achieve. In this paper, through mathematical assessment, we provided the optimal blasting design, respecting desirable fragmentation, reducing negative effects and minimizing the costs of these activities. 


\section{Materials and Methods}

The most suitable way to describe the problem of alternative ranking is the decisionmaking matrix, abbreviated decision matrix:

$$
D=\left[x_{i j}\right]_{m \times n}=\left[\begin{array}{ccccc}
A / C & C_{1} & C_{2} & \ldots & C_{n} \\
A_{1} & x_{11} & x_{12} & \ldots & x_{1 j} \\
A_{2} & x_{21} & x_{22} & \ldots & x_{2 j} \\
\vdots & \vdots & \vdots & \ddots & \vdots \\
A_{m} & x_{m 1} & x_{m 2} & \ldots & x_{m n}
\end{array}\right]
$$

where:

$A=\left[A_{1}, A_{2}, \ldots, A_{m}\right]$-a given set of alternatives, where $m$ is the total number of alternatives

$C=\left[C_{1}, C_{2}, \ldots, C_{n}\right]$-a given set of criteria, where $n$ is the total number of criteria

$\left[x_{i j}\right]_{m \times n}$-an assessment of alternative $A_{i}$ with respect to a set of criteria

Some of the criteria should be maximized while some minimized. If we face the problem, where all criteria tend to achieve max or min value, then in an artificial way one of the criteria is expressed by its reciprocal value. In this way, one criterion is being transformed to its opposite desired extreme value, while the rest stay the same. The purpose of such a transformation is to create an appropriate environment to decompose (separate) the decision-making space in two independent components (max and min components). The existence of max and min criteria is a necessary precondition for methods working properly.

The procedure of extracting the rank of alternatives from the decision matrix is composed of the following steps:

Step 1: Normalization of input data

Each criterion is defined by its dimension: this means that we are facing the multidimensional problem. In such an environment it is very hard to make decisions. To avoid such difficulties, it is necessary to transform the multidimensional into a nondimensional decision space. For the max criteria we perform the following way of normalization:

$$
r_{i j}=\frac{x_{i j}}{\max _{i}\left(x_{i j}\right)}, \forall i \in[1,2, \ldots, m] \wedge j \in S_{\max }
$$

while for the min criteria:

$$
r_{i j}=\frac{\min _{i}\left(x_{i j}\right)}{x_{i j}}, \forall i \in[1,2, \ldots, m] \wedge j \in S_{\text {min }}
$$

where:

$S_{\max }$-a set of criteria that should be maximized

$S_{\min }$-a set of criteria that should be minimized

The process of normalization yields the normalized decision matrix:

$$
R=\left[r_{i j}\right]_{m \times n}=\left[\begin{array}{ccccc}
A / C & C_{1} & C_{2} & \ldots & C_{n} \\
A_{1} & r_{11} & r_{12} & \ldots & r_{1 j} \\
A_{2} & r_{21} & r_{22} & \ldots & r_{2 j} \\
\vdots & \vdots & \vdots & \ddots & \vdots \\
A_{m} & r_{m 1} & r_{m 2} & \ldots & r_{m n}
\end{array}\right]
$$

Step 2: Weighted normalization 
For each normalized assessment $r_{i j}$ do the weighted normalization as follows:

$$
u_{i j}=w_{j} r_{i j}, \forall i \in[1,2, \ldots, m], \forall j \in[1,2, \ldots, n]
$$

The outcome of weighted normalization is the weighted normalized matrix:

$$
U=\left[u_{i j}\right]_{m \times n}=\left[\begin{array}{ccccc}
A / C & C_{1} & C_{2} & \ldots & C_{n} \\
A_{1} & u_{11} & u_{12} & \ldots & u_{1 j} \\
A_{2} & u_{21} & u_{22} & \ldots & u_{2 j} \\
\vdots & \vdots & \vdots & \ddots & \vdots \\
A_{m} & u_{m 1} & u_{m 2} & \ldots & u_{m n}
\end{array}\right]
$$

To avoid subjectivity in the process of weighted normalization it is necessary to apply some objective method. In this paper, Shannon's entropy method is used to define the weights of criteria [42]. Compute the entropy $E_{j}$ by:

$$
E_{j}=-\frac{1}{\ln (m)} \sum_{i=1}^{m}\left(\frac{x_{i j}}{\sum_{i=1}^{m} x_{i j}} \ln \left(\frac{x_{i j}}{\sum_{i=1}^{m} x_{i j}}\right)\right), \forall i \in[1,2, \ldots, m], \forall j \in[1,2, \ldots, n]
$$

The degree of diversification is calculated as:

$$
d_{j}=1-E_{j}, \forall j \in[1,2, \ldots, n]
$$

Finally, the degree of criteria importance, i.e., criteria weights is defined as follows:

$$
w_{j}=\frac{d_{j}}{\sum_{j=1}^{n} d_{j}}
$$

The sum of weights must equal one; $\sum_{j=1}^{n} w_{j}=1$.

Step 3: Optimal alternative determination

Determine each element of the optimal alternative as follows:

$$
q_{j}=\max \left(u_{i j} \mid 1 \leq j \leq n\right), \forall i \in[1,2, \ldots, m]
$$

Optimal alternative is represented by the following set:

$$
Q=\left\{q_{1}, q_{2}, \ldots, q_{j}\right\}, j=1,2, \ldots, n
$$

Step 4: Decomposition of the optimal alternative

This step implies decomposition of the optimal alternative in the two subsets or two components. The set $Q$ can be represented as the union of the two subsets:

$$
Q=Q^{\max } \cup Q^{\min }
$$

If $k$ represents the total number of criteria which should be maximized, then $h=n-k$ represents the total number of criteria which should be minimized. Hence, the optimal alternative is defined as:

$$
Q=\left\{q_{1}, q_{2}, \ldots, q_{k}\right\} \cup\left\{q_{1}, q_{2}, \ldots, q_{h}\right\} ; k+h=j
$$

Step 5: Decomposition of the alternative

Similarly, to Step 4 we perform decomposition of each alternative:

$$
U_{i}=U_{i}^{\max } \cup U_{i}^{\min }, \forall i \in[1,2, \ldots, m]
$$




$$
U_{i}=\left\{u_{i 1}, u_{i 2}, \ldots, u_{i k}\right\} \cup\left\{u_{i 1}, u_{i 2}, \ldots, u_{i h}\right\}, \forall i \in[1,2, \ldots, m]
$$

Step 6: Magnitude of component

For each component of the optimal alternative, calculate the magnitude defined by:

$$
\begin{aligned}
& Q_{k}=\sqrt{q_{1}^{2}+q_{2}^{2}+. .+q_{k}^{2}} \\
& Q_{h}=\sqrt{q_{1}^{2}+q_{2}^{2}+. .+q_{h}^{2}}
\end{aligned}
$$

The same approach is applied for each alternative.

$$
\begin{aligned}
& U_{i k}=\sqrt{u_{i 1}^{2}+u_{i 2}^{2}+\ldots+u_{i k}^{2}}, \forall i \in[1,2, . ., m] \\
& U_{i h}=\sqrt{u_{i 1}^{2}+u_{i 2}^{2}+\ldots+u_{i h}^{2}}, \forall i \in[1,2, . ., m]
\end{aligned}
$$

From this point, we represent two methods developed to create the rank of alternatives. The first method is based on the trace of a matrix. The second method uses the similarity between the perimeter of the optimal alternative and the perimeter of the alternative.

Step 6.1: Multiple Criteria Ranking by Alternative Trace (MCRAT)

Create the matrix $F$ composed of optimal alternative components:

$$
F=\left[\begin{array}{cc}
Q_{k} & 0 \\
0 & Q_{h}
\end{array}\right]
$$

In addition, create the matrix $G_{i}$ composed of alternative components:

$$
G_{i}=\left[\begin{array}{cc}
U_{i k} & 0 \\
0 & U_{i h}
\end{array}\right], \forall i \in[1,2, \ldots, m]
$$

If $T_{i}$ is a matrix obtained by the product of matrix $F$ and $G_{i}$ :

$$
T_{i}=F \times G_{i}=\left[\begin{array}{cc}
t_{11 ; i} & 0 \\
0 & t_{22 ; i}
\end{array}\right], \forall i \in[1,2, \ldots, m]
$$

Then, the trace of the matrix $T_{i}$ is as follows:

$$
\operatorname{tr}\left(T_{i}\right)=t_{11 ; i}+t_{22 ; i}, \forall i \in[1,2, \ldots, m]
$$

Alternatives are now ranked according to the descending order of $\operatorname{tr}\left(T_{i}\right)$.

Step 6.2: Ranking the Alternatives by Perimeter Similarity (RAPS)

Perimeter of the optimal alternative is expressed as the perimeter of the right-angle triangle. Components $Q_{k}$ and $Q_{h}$ represent the base and perpendicular side of this triangle, respectively.

$$
P=Q_{k}+Q_{h}+\sqrt{Q_{k}^{2}+Q_{k}^{2}}
$$

Perimeter of each alternative is calculated the same way:

$$
P_{i}=U_{i k}+U_{i h}+\sqrt{U_{i k}^{2}+U_{i h}^{2}}
$$

Perimeter similarity represents the ratio between the perimeter of each alternative and optimal alternative:

$$
P S_{i}=\frac{P_{i}}{P}, \forall i \in[1,2, \ldots, m]
$$

Alternatives are now ranked according to the descending order of $P S_{i}$. 
Figure 1 represents all of the abovementioned steps of extracting the rank of alternatives from the decision matrix.

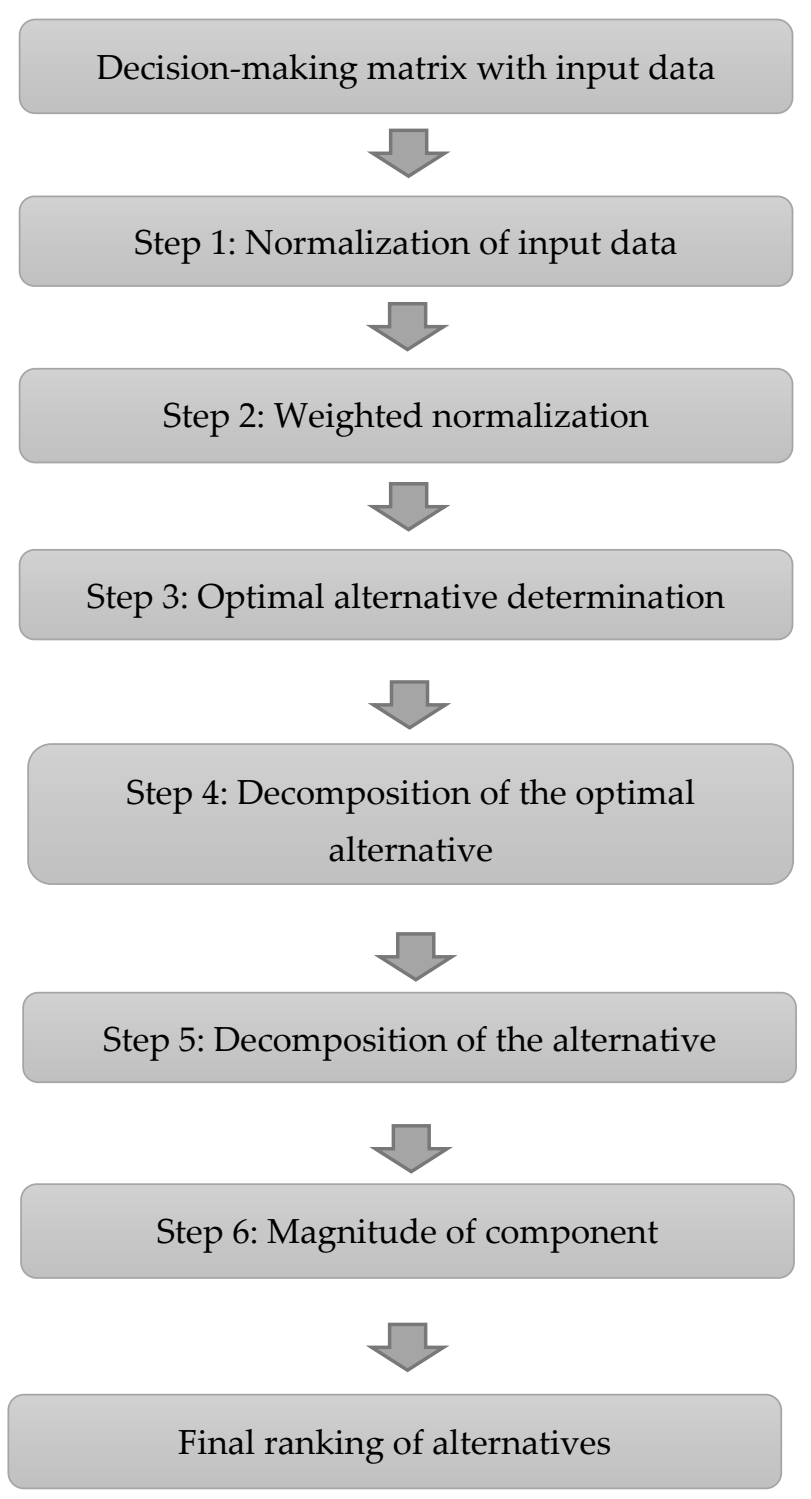

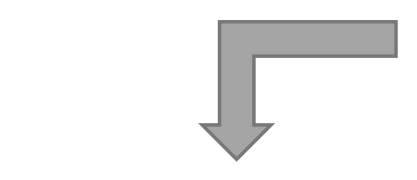

Step 6.1: Multiple-Criteria Ranking by Alternative Trace (MCRAT)
Step 6.2: Ranking the Alternatives by Perimeter Similarity (RAPS)

Figure 1. MCRAT and RAPS flow chart.

\section{Mining Problem}

In this paper, a hypothetical dacite mine is considered, with an annual capacity of $300,000.00$ tons of dacite in different fractions. To separate dacite from massif drilling, blasting operations are used.

It is necessary to consider all possible aspects in the design of drilling and blasting in order to minimize the impact of these operations on the environment and at the same time keep the costs of exploitation within the limits of acceptability. 
The available equipment has the possibility to drill holes with three different diameters: 76-, 89- and 106-mm. The maximum size of fragmented dacite rock acceptable for crusher is $850 \mathrm{~mm}$. The main explosive which is in use for blasting is based on TNT and ammonium nitrate, with characteristics which are suitable for blasting of hard rocks like dacite. The projected working slope is $75^{\circ}$ and bench height is $15 \mathrm{~m}$. For this purpose, 12 different blasting patterns are calculated, and their geometrical parameters are shown in Table 2.

Table 2. Parameters of blasting patterns.

\begin{tabular}{ccccccc}
\hline Alternative & Hole Diameter $(\mathbf{m m})$ & Hole Length $(\mathbf{m})$ & Stemming $(\mathbf{m})$ & Burden $(\mathbf{m})$ & Spacing $(\mathbf{m})$ & Subdrill $(\mathbf{m})$ \\
\hline A1 & 76 & 16.3 & 2.6 & 2.6 & 2.6 & 0.76 \\
A2 & 76 & 16.7 & 2.6 & 2.6 & 3.6 & 3.0 \\
A3 & 76 & 16.3 & 3.0 & 3.0 & 3.0 & 0.14 \\
A4 & 76 & 16.7 & 3.0 & 2.9 & 3.9 & 1.14 \\
A5 & 89 & 16.4 & 2.9 & 3.5 & 0.89 \\
A6 & 89 & 16.4 & 3.5 & 2.9 & 3.9 & 0.89 \\
A7 & 89 & 16.9 & 2.9 & 3.5 & 3.5 & 1.34 \\
A8 & 89 & 16.9 & 3.5 & 3.4 & 3.4 & 1.06 \\
A9 & 106 & 16.6 & 3.4 & 3.4 & 4.0 & 1.56 \\
A10 & 106 & 17.1 & 3.4 & 4.0 & 4.0 & 1.06 \\
A11 & 106 & 16.6 & 4.0 & 4.0 & & 4.0 \\
A12 & 106 & 17.1 & 4.0 & & & 1.56 \\
\hline
\end{tabular}

Represented in Table 2 are 12 alternatives used for this purpose, where every alternative is described with geometrical parameters of the blasting pattern. Those geometrical specifications are hole diameter and length, stemming, burden, spacing and subdrill. Hole diameter depends on the available equipment, drill rig, that the mine has. In this case, there are three possibilities for the diameter value for the hole: 76, 89 and $106 \mathrm{~mm}$. Hole length depends on bench height and its slope.

After putting explosives in the blast hole, the rest of the space in the hole is usually filled up with specific material; this process represents stemming. The task of stemming is to prevent the blowing of gases from the hole and thus enable the use of gas energy for the crushing of rock mass [35].

Burden is the distance from a single row to the face of the excavation and spacing represents the lateral distance on centers between holes in a row. Subdrill is part of blasthole below floor level of the bench, with the purpose of ensuring the crushing of the rock in the lower part of the bench and providing successful blasting of the bench [35].

All these parameters and their well-chosen combination lead to a successful blasting process. If some of these parameters are not suitable and do not match with the rest of the geometrical parameters, blasting will not provide convenient fragmentation or may cause some negative effect to the environment or can increase the cost of exploitation of raw materials. Therefore, it is important to align parameters and make sure that the exploitation process runs uninterrupted.

In accordance with the aims which are important to achieve in this example, five criteria are chosen to consider when selecting the best alternative. In Table 3 these criteria are illustrated for all 12 alternatives individually.

Table 3. Criteria used for selecting optimal blasting pattern.

\begin{tabular}{cccccc}
\hline Alternative & Powder Factor, $\mathbf{~ k g} / \mathbf{m}^{\mathbf{3}}$ & Fragmentation, $\mathbf{1 / \mathbf { m m }}$ & Fly Rock, $\mathbf{m}$ & Air Shock, $\mathbf{m}$ & Cost, $\boldsymbol{\epsilon} /$ Pattern \\
\hline A1 & 0.4 & 0.002353 & 347 & 101.5 & 1.500 \\
A2 & 0.41 & 0.001208 & 348 & 105 & 1500 \\
A3 & 0.29 & 0.002353 & 364 & 97.5 & 1500 \\
A4 & 0.3 & 0.001208 & 385 & 100 & 1500 \\
A5 & 0.43 & 0.002353 & 335 & 125 & 1600 \\
A6 & 0.28 & 0.002353 & 365 & 130 & 1600 \\
A7 & 0.45 & 0.001208 & 310 & 140 & 1700 \\
\hline
\end{tabular}


Table 3. Cont.

\begin{tabular}{cccccc}
\hline Alternative & Powder Factor, $\mathbf{~ k g} / \mathbf{m}^{\mathbf{3}}$ & Fragmentation, $\mathbf{1} \mathbf{m m}$ & Fly Rock, $\mathbf{m}$ & Air Shock, $\mathbf{m}$ & Cost, $\boldsymbol{\epsilon} /$ Pattern \\
\hline A8 & 0.29 & 0.002353 & 320 & 135 & 1600 \\
A9 & 0.4 & 0.000619 & 315 & 175 & 1700 \\
A10 & 0.42 & 0.000619 & 325 & 180 & 1700 \\
A11 & 0.28 & 0.001208 & 280 & 165 & 1700 \\
A12 & 0.29 & 0.001208 & 220 & 170 & 1700 \\
\hline
\end{tabular}

In Table 3, some of the most important products of explosion during blasting are shown. Some of them are important for the production process and others for environmental protection or economic aspects. Values in Table 3 are the result of application of every one of the 12 alternatives described in Table 2.

Powder factor is defined as an amount of explosive which will be enough to crush one cubic meter of rock [35]. Powder factor is classified as a minimum value because of blasting cost: the higher the powder factor, the higher the cost of blasting.

The second criterion for selecting the most suitable pattern is fragmentation. Bad fragmentation of blasted rocks has a very significant influence on costs related to the production phases after primary blasting. In this case, desired fragmentation is specified by equipment used for the crushing of blasted rock. Fragment size of blasted rock is a function of site properties, blasting geometry, explosive strength, etc. In such an environment it is impossible to estimate the precise value of fragments. Values used in this calculation are approximate values of the biggest rock fragments obtained from the blasting process. The reciprocal value of fragmentation is used according to Section 2 of this paper for the purpose of creating an environment in an artificial way, where two components can be separated in the decomposition process. Fragmentation expressed this way, tends to be the maximum.

Fly rock is one of the most undesired effects of blasting, that can endanger human beings and objects nearby blasting operations. This criterion should be defined as minimum because the lower the safety distance is, the bigger the chance to avoid the consequences of possible fly rock damage.

Air shock is one of the negative effects of blasting and it is characterized as minimum. This criterion represents the safety distance from the blast zone, where there are no possibilities the shock makes some damage to people or objects.

The fifth criterion used for selection is costs of every suggested pattern. Total costs for each pattern include labor force, energies, materials, etc. Costs are expressed in Euros. For optimal patterns, the most desired are the minimum costs.

The process of blasting includes preparation of patterns defined with geometrical parameters like those in Table 2. When the pattern is ready, the explosive has to be placed in holes and then initiated and detonated. After that step, there is a very strong chemical reaction and products of explosion like energy, gases with very high temperatures and pressure spread. That energy provides the crushing of rocks and desired fragmentation but also produces negative effects like ground vibration, fly rock and air shock [35].

\section{Validity Test of Novel Methods}

In this section, the correlation between novel methods and existing MCDM methods, which are already in use, is demonstrated. Examples are borrowed from researchers who already published their examinations.

\subsection{The First Example for Testing}

Zavadskas and Turskis [25] used MCDM methods to evaluate 14 rooms according to six criteria for inside climate evaluation, as shown in Table 4. Hajiagha et al. [24] provided a solution of this problem by developing the TAOV method and presenting these results. 
Table 4. Input data.

\begin{tabular}{|c|c|c|c|c|c|c|}
\hline \multirow{2}{*}{ Room No. } & $C_{1}$ & $C_{2}$ & $C_{3}$ & $C_{4}$ & $C_{5}$ & $C_{6}$ \\
\hline & $\max$ & Max & $\operatorname{Max}$ & $\max$ & $\min$ & $\min$ \\
\hline 1. & 7.6 & 46 & 18 & 390 & 0.10 & 11 \\
\hline 2. & 5.5 & 32 & 21 & 360 & 0.05 & 11 \\
\hline 3. & 5.3 & 32 & 21 & 290 & 0.05 & 11 \\
\hline 4. & 5.7 & 37 & 19 & 270 & 0.05 & 9 \\
\hline 5. & 4.2 & 38 & 19 & 240 & 0.10 & 8 \\
\hline 6. & 4.4 & 38 & 19 & 260 & 0.10 & 8 \\
\hline 7. & 3.9 & 42 & 16 & 270 & 0.10 & 5 \\
\hline 8. & 7.9 & 44 & 20 & 400 & 0.05 & 6 \\
\hline 9. & 8.1 & 44 & 20 & 380 & 0.05 & 6 \\
\hline 10. & 4.5 & 46 & 18 & 320 & 0.10 & 7 \\
\hline 11. & 5.7 & 48 & 20 & 320 & 0.05 & 11 \\
\hline 12. & 5.2 & 48 & 20 & 310 & 0.05 & 11 \\
\hline 13. & 7.1 & 49 & 19 & 280 & 0.10 & 12 \\
\hline 14. & 6.9 & 50 & 16 & 250 & 0.05 & 10 \\
\hline Weight & 0.21 & 0.16 & 0.26 & 0.17 & 0.12 & 0.08 \\
\hline
\end{tabular}

Criteria used to evaluate rooms by microclimate conditions were:

C1-the amount of air per head (should be maximized);

C2-relative air humidity (should be maximized);

C3-air temperature (should be maximized);

C4-illumination during work hours (should be maximized);

C5-rate of air flow (should be minimized);

C6-dew point (should be minimized).

Weights of all these criteria were based on the estimation of numerous experts in this field and determined by the method of pairwise comparison. The obtained weight vector of criteria is shown in Table 4.

For the same numerical example, MCRAT and RAPS were applied, and the ranking by these two novel methods and a variety of other methods is presented in Table 5.

Table 5. Room ranking by different MCDM methods.

\begin{tabular}{ccccccccccc}
\hline Room No. & MCRAT & RAPS & TAOV & ARAS & SAW & TOPSIS & COPRAS & VIKOR & WASPAS & ELECTREE \\
\hline 1. & 3 & 4 & 3 & 4 & 3 & 3 & 3 & 6 & 4 & 3 \\
2. & 8 & 7 & 6 & 6 & 5 & 7 & 7 & 5 & 6 & 4 \\
3. & 11 & 10 & 10 & 10 & 8 & 10 & 10 & 8 & 10 & 6 \\
4. & 9 & 9 & 11 & 9 & 10 & 9 & 9 & 9 & 9 & 9 \\
5. & 14 & 14 & 14 & 14 & 13 & 13 & 13 & 13 & 14 & 12 \\
6. & 13 & 13 & 13 & 13 & 12 & 12 & 12 & 12 & 12 & 13 \\
7. & 12 & 12 & 12 & 12 & 14 & 14 & 14 & 14 & 13 & 14 \\
8. & 1 & 1 & 1 & 2 & 1 & 1 & 1 & 1 & 1 & 1 \\
9. & 2 & 2 & 2 & 1 & 2 & 2 & 2 & 2 & 2 & 2 \\
10. & 10 & 11 & 9 & 11 & 11 & 11 & 11 & 10 & 11 & 10 \\
11. & 5 & 5 & 5 & 3 & 4 & 4 & 4 & 3 & 3 & 5 \\
12. & 7 & 6 & 7 & 5 & 6 & 8 & 5 & 4 & 5 & 7 \\
13. & 6 & 8 & 4 & 8 & 7 & 6 & 8 & 7 & 8 & 7 \\
14. & 4 & 3 & 8 & 7 & 9 & 5 & 6 & 11 & 7 \\
\hline
\end{tabular}

Table 6 illustrates correlation degrees between novel methods and other methods for this numerical example.

From this table it can be seen that the least correlation of the MCRAT method is 79\% with the VIKOR method. Correlation with the SAW method is $88 \%$, while the MCRAT method has an over $90 \%$ correlation with all other methods in the table. The RAPS method 
is $78 \%$ with ELECTRE, which is the least correlation. Next are VIKOR with $80 \%$, SAW with $88 \%$ and TAOV with $89 \%$, while all others have over $90 \%$ of correlation with RAPS.

Table 6. Degree of correlation for different methods.

\begin{tabular}{|c|c|c|c|c|c|c|c|c|c|c|}
\hline Correlation & MCRAT & RAPS & TAOV & ARAS & SAW & TOPSIS & COPRAS & VIKOR & WASPAS & ELECTRE \\
\hline MCRAT & - & 0.98 & 0.93 & 0.93 & 0.88 & 0.97 & 0.95 & 0.79 & 0.93 & 0.93 \\
\hline RAPS & & - & 0.89 & 0.95 & 0.88 & 0.96 & 0.96 & 0.80 & 0.95 & 0.78 \\
\hline TAOV & & & - & 0.92 & 0.94 & 0.93 & 0.91 & 0.88 & 0.92 & 0.87 \\
\hline ARAS & & & & - & 0.95 & 0.94 & 0.97 & 0.92 & 0.99 & 0.88 \\
\hline SAW & & & & & - & 0.93 & 0.96 & 0.96 & 0.96 & 0.96 \\
\hline TOPSIS & & & & & & - & 0.97 & 0.84 & 0.95 & 0.85 \\
\hline COPRAS & & & & & & & - & 0.90 & 0.99 & 0.87 \\
\hline VIKOR & & & & & & & & - & 0.93 & 0.93 \\
\hline WASPAS & & & & & & & & & - & 0.89 \\
\hline ELECTRE & & & & & & & & & & - \\
\hline
\end{tabular}

\subsection{The Second Example for Testing}

Stanujkic et al. [43] used multiple criteria decision-making methods on the example of ranking Serbian banks. Criteria used for evaluation of bank ranking (Table 7) were:

L1-Cash and cash equivalent + cash due from financial institutions/total deposits (should be maximized)

L2-Total loans/total deposits (should be maximized)

L3-Net cash flow from operating activities/total cash flow (should be maximized)

E1-Operating cost/operating income (should be minimized)

E2-Provisions for loans/net interest income (should be minimized)

E3-Operating income/total number of employees (should be maximized)

P1-Profit before taxes/equity (should be maximized)

P2-Profit before taxes/asset (should be maximized)

P3-Profit before taxes/operating income (should be maximized)

C1-Total liabilities (should be minimized)

C2-Equity/loans (should be maximized)

C3-Total deposits/equity (should be minimized)

C4-Capital adequacy ratio (should be maximized)

Table 7. Input matrix.

\begin{tabular}{cccccccccccccc}
\hline & Max & Max & Max & Min & Min & Max & Max & Max & Max & Min & Max & Min & Max \\
\hline & L1 & L2 & L3 & E1 & E2 & E3 & P1 & P2 & P3 & C1 & C2 & C3 & C4 \\
\hline A1 & 2.5 & 0.76 & 0.26 & 0.49 & 0.18 & 5.01 & 0.012 & 0.11 & 0.179 & 5.36 & 0.26 & 4.97 & 18.7 \\
A2 & 1.47 & 1.02 & 0.29 & 0.28 & 0.22 & 6.51 & 0.016 & 0.101 & 0.225 & 2.69 & 0.48 & 2.02 & 29 \\
A3 & 1.31 & 1.36 & 0.18 & 0.43 & 0.1 & 12.65 & 0.026 & 0.23 & 0.338 & 4.2 & 0.28 & 2.57 & 17.1 \\
A4 & 1.34 & 1.06 & 0.18 & 0.43 & 0.16 & 24.58 & 0.043 & 0.22 & 0.527 & 2.2 & 0.45 & 2.06 & 32 \\
A5 & 1.57 & 1.5 & 0.24 & 0.44 & 0.13 & 12.9 & 0.02 & 0.1 & 0.38 & 3.57 & 0.34 & 1.91 & 25.9 \\
Weight & 0.161 & 0.054 & 0.161 & 0.08 & 0.032 & 0.013 & 0.039 & 0.073 & 0.014 & 0.081 & 0.047 & 0.062 & 0.185 \\
\hline
\end{tabular}

After application of the MCRAT and RAPS methods on this example, ranking was obtained and calculated regarding correlation of existing methods applied in this example and novel methods. Results are shown in Table 8.

In Table 8 it can be seen that the highest correlation of novel methods is with VIKOR and GRA (MinMax). It is a very interesting fact that MCRAT and RAPS have a negative correlation with GRA(T), as with all other methods. It indicates the capability of the proposed methods to rank alternatives in a very successful way. 
Table 8. Correlation of applied and novel methods.

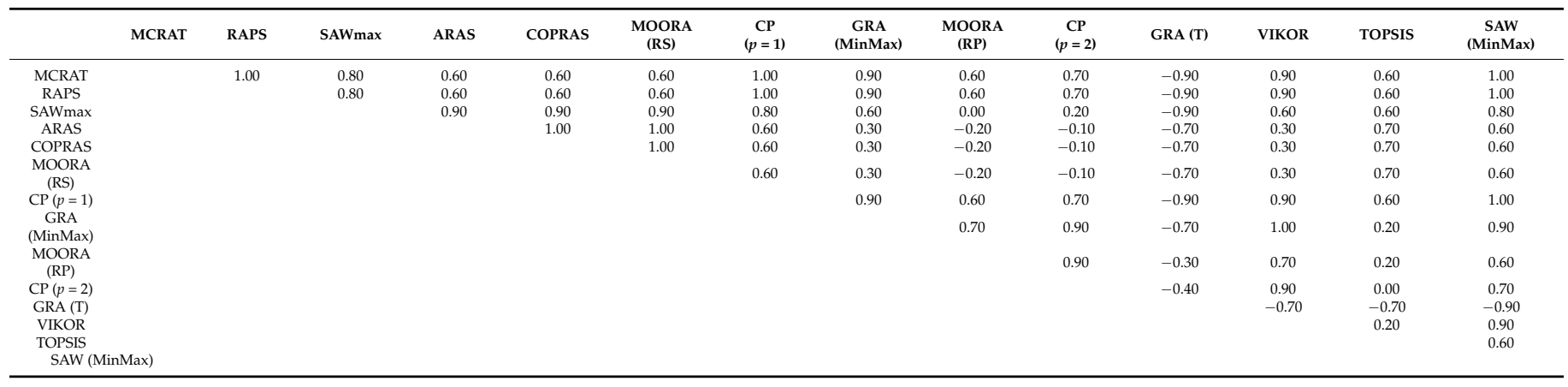

\section{Numerical Example for the Mining Problem}

For determination of the most economical and reliable blasting pattern and to satisfy environmental issues we applied the above explained two novel methods MCRAT and RAPS based on the MCDM process. Every pattern which is used in the selecting process has determined values of each criterion.

Selecting an appropriate blasting pattern is very important because an incorrect choice causes many problems such as disruption of the mining process, raising of costs and safety issues for employees and the environment.

After presenting the results of the application of each pattern and showing values for every criterion considered, Table 9 shows the classification of each criterion to max or min.

Table 9. Input decision matrix.

\begin{tabular}{cccccc}
\hline \multirow{2}{*}{ Alternative/Criterion } & $\boldsymbol{C}_{\mathbf{1}}$ & $\boldsymbol{C}_{\mathbf{2}}$ & $\boldsymbol{C}_{\mathbf{3}}$ & $\boldsymbol{C}_{\mathbf{4}}$ & $\boldsymbol{C}_{\mathbf{5}}$ \\
\cline { 2 - 6 } & $\mathbf{M i n}$ & $\mathbf{M a x}$ & $\mathbf{M i n}$ & $\mathbf{M i n}$ & $\mathbf{M i n}$ \\
\hline A1 & 0.40 & 0.00235 & 347 & 101.5 & 1500 \\
A2 & 0.41 & 0.00121 & 348 & 105 & 1500 \\
A3 & 0.29 & 0.00235 & 364 & 97.5 & 1500 \\
A4 & 0.30 & 0.00121 & 385 & 100 & 1500 \\
A5 & 0.43 & 0.00235 & 335 & 125 & 1600 \\
A6 & 0.28 & 0.00235 & 365 & 130 & 1600 \\
A7 & 0.45 & 0.00121 & 310 & 140 & 1700 \\
A8 & 0.29 & 0.00235 & 320 & 135 & 1600 \\
A9 & 0.40 & 0.00062 & 315 & 175 & 1700 \\
A10 & 0.42 & 0.00062 & 325 & 180 & 1700 \\
A11 & 0.28 & 0.00121 & 280 & 165 & 1700 \\
A12 & 0.29 & 0.00121 & 220 & 170 & 1700 \\
\hline
\end{tabular}

The next step for decision making was to normalize input data. Table 10 shows the normalization of the criteria in Table 9.

Table 10. Normalized decision matrix.

\begin{tabular}{cccccc}
\hline \multirow{2}{*}{ Alternative/Criterion } & $\boldsymbol{C}_{\mathbf{1}}$ & $\boldsymbol{C}_{\mathbf{2}}$ & $\boldsymbol{C}_{\mathbf{3}}$ & $\boldsymbol{C}_{\mathbf{4}}$ & $\boldsymbol{C}_{\mathbf{5}}$ \\
\cline { 2 - 6 } & $\mathbf{M i n}$ & $\mathbf{M a x}$ & $\mathbf{M i n}$ & $\mathbf{M i n}$ & $\mathbf{M i n}$ \\
\hline A1 & 0.7000 & 1.0000 & 0.6340 & 0.9606 & 1.0000 \\
A2 & 0.6829 & 0.5133 & 0.6322 & 0.9286 & 1.0000 \\
A3 & 0.9655 & 1.0000 & 0.6044 & 1.0000 & 1.0000 \\
A4 & 0.9333 & 0.5133 & 0.5714 & 0.9750 & 1.0000 \\
A5 & 0.6512 & 1.0000 & 0.6567 & 0.7800 & 0.9375 \\
A6 & 1.0000 & 1.0000 & 0.6027 & 0.7500 & 0.9375 \\
A7 & 0.6222 & 0.5133 & 0.7097 & 0.6964 & 0.8824 \\
A8 & 0.9655 & 1.0000 & 0.6875 & 0.7222 & 0.9375 \\
A9 & 0.7000 & 0.2630 & 0.6984 & 0.5571 & 0.8824 \\
\hline
\end{tabular}


Table 10. Cont.

\begin{tabular}{cccccc}
\hline \multirow{2}{*}{ Alternative/Criterion } & $\boldsymbol{C}_{\mathbf{1}}$ & $\boldsymbol{C}_{\mathbf{2}}$ & $\boldsymbol{C}_{\mathbf{3}}$ & $\boldsymbol{C}_{\mathbf{4}}$ & $\boldsymbol{C}_{\mathbf{5}}$ \\
\cline { 2 - 6 } & Min & Max & Min & Min & Min \\
\hline A10 & 0.6667 & 0.2630 & 0.6769 & 0.5417 & 0.8824 \\
A11 & 1.0000 & 0.5133 & 0.7857 & 0.5909 & 0.8824 \\
A12 & 0.9655 & 0.5133 & 1.0000 & 0.5735 & 0.8824 \\
\hline
\end{tabular}

For determining the weights of each criterion, we used Shannon's entropy method (42), and in that way avoided subjectivity of this process. Table 11 shows weights for each criterion. They are also presented in Figure 2.

Table 11. By applying Shannon's entropy method, the following weights of criteria were obtained.

\begin{tabular}{ccccccc}
\hline \multirow{2}{*}{ Weight/Criterion } & $\boldsymbol{C}_{\mathbf{1}}$ & $\boldsymbol{C}_{\mathbf{2}}$ & $\boldsymbol{C}_{\mathbf{3}}$ & $\boldsymbol{C}_{\mathbf{4}}$ & $\boldsymbol{C}_{\mathbf{5}}$ \\
\cline { 2 - 7 } & $\mathbf{w 1}$ & $\mathbf{w 2}$ & $\mathbf{w 3}$ & $\mathbf{w 4}$ & $\mathbf{w 5}$ \\
\hline $\mathrm{W}$ & 0.1197 & 0.6482 & 0.0597 & 0.1627 & 0.0098 \\
\hline
\end{tabular}

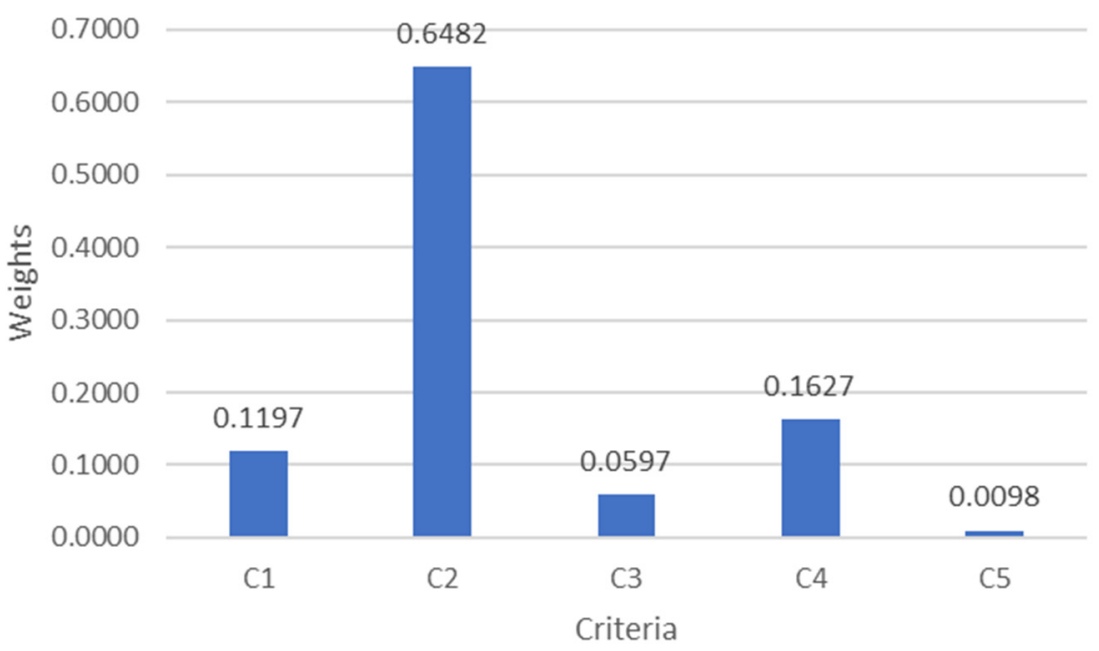

Figure 2. Obtained weights of criteria with Shannon's entropy method.

After applying Shannon's entropy method and getting weights for each criterion, the next step was to perform a weighted normalized matrix as shown in Table 10. These results are presented in Table 12.

Table 12. Weighted normalized decision matrix.

\begin{tabular}{cccccc}
\hline \multirow{2}{*}{ Alternative/Criterion } & $\boldsymbol{C}_{\mathbf{1}}$ & $\boldsymbol{C}_{\mathbf{2}}$ & $\boldsymbol{C}_{\mathbf{3}}$ & $\boldsymbol{C}_{\mathbf{4}}$ & $\boldsymbol{C}_{\mathbf{5}}$ \\
\cline { 2 - 6 } & $\mathbf{M i n}$ & $\mathbf{M a x}$ & $\mathbf{M i n}$ & $\mathbf{M i n}$ & Min \\
\hline A1 & 0.0838 & 0.6482 & 0.0378 & 0.1562 & 0.0098 \\
A2 & 0.0817 & 0.3327 & 0.0377 & 0.1510 & 0.0098 \\
A3 & 0.1155 & 0.6482 & 0.0361 & 0.1627 & 0.0098 \\
A4 & 0.1117 & 0.3327 & 0.0341 & 0.1586 & 0.0098 \\
A5 & 0.0779 & 0.6482 & 0.0392 & 0.1269 & 0.0092 \\
A6 & 0.1197 & 0.6482 & 0.0360 & 0.1220 & 0.0092 \\
A7 & 0.0745 & 0.3327 & 0.0423 & 0.1133 & 0.0086 \\
A8 & 0.1155 & 0.6482 & 0.0410 & 0.1175 & 0.0092 \\
A9 & 0.0838 & 0.1705 & 0.0417 & 0.0906 & 0.0086 \\
A10 & 0.0798 & 0.1705 & 0.0404 & 0.0881 & 0.0086 \\
A11 & 0.1197 & 0.3327 & 0.0469 & 0.0961 & 0.0086 \\
A12 & 0.1155 & 0.3327 & 0.0597 & 0.0933 & 0.0086 \\
\hline
\end{tabular}


The next step involved determining the optimal alternative by applying Formula 7. Results of this step are shown in Table 13.

Table 13. Optimal alternative.

\begin{tabular}{cccccc}
\hline \multirow{3}{*}{ Optimal Alternative /Criterion } & $C_{1}$ & $C_{2}$ & $C_{3}$ & $C_{4}$ & $C_{5}$ \\
\cline { 2 - 6 } & Min & Max & Min & Min & Min \\
\cline { 2 - 6 } & $\boldsymbol{q}_{1}$ & $\boldsymbol{q}_{2}$ & $\boldsymbol{q}_{3}$ & $\boldsymbol{q}_{4}$ & $\boldsymbol{q}_{5}$ \\
\hline$Q$ & 0.1197 & 0.6482 & 0.0597 & 0.1627 & 0.0098 \\
\hline
\end{tabular}

Table 14 represents the decomposition of the optimal alternative.

Table 14. Decomposition of the optimal alternative.

\begin{tabular}{cccccc}
\hline & $C_{1}$ & $C_{2}$ & $C_{3}$ & $C_{4}$ & $C_{5}$ \\
\cline { 2 - 6 } Optimal Alternative/Criterion & $\min$ & $\max$ & $\min$ & $\min$ & $\min$ \\
\cline { 2 - 6 } & $\boldsymbol{q}_{1}$ & $\boldsymbol{q}_{2}$ & $\boldsymbol{q}_{3}$ & $\boldsymbol{q}_{4}$ & $\boldsymbol{q}_{5}$ \\
\hline$Q^{\max }$ & - & 0.6482 & - & - & - \\
$Q^{\min }$ & 0.1197 & - & 0.0597 & 0.1627 & 0.0098 \\
\hline
\end{tabular}

In Table 15, the decomposition of each of the alternatives for the selecting process for obtaining an optimal solution for the blasting design is presented.

Table 15. Decomposition of alternatives.

\begin{tabular}{|c|c|c|c|c|c|}
\hline \multirow{3}{*}{ Alternative/Criterion } & $C_{1}$ & $C_{2}$ & $C_{3}$ & $C_{4}$ & $C_{5}$ \\
\hline & Min & $\operatorname{Max}$ & Min & Min & Min \\
\hline & $u_{1}$ & $u_{2}$ & $u_{3}$ & $u_{4}$ & $u_{5}$ \\
\hline $\mathrm{A} 1 U^{\max }$ & - & 0.6482 & - & - & - \\
\hline $\mathrm{A} 1 U^{\min }$ & 0.0838 & & 0.0378 & 0.1562 & 0.0098 \\
\hline $\mathrm{A} 2 U^{\max }$ & - & 0.3327 & - & - & - \\
\hline A2 $U^{\min }$ & 0.0817 & & 0.0377 & 0.1510 & 0.0098 \\
\hline A3 $U^{\max }$ & - & 0.6482 & - & - & - \\
\hline A3 $U^{\min }$ & 0.1155 & & 0.0361 & 0.1627 & 0.0098 \\
\hline $\mathrm{A} 4 U^{\max }$ & - & 0.3327 & - & - & - \\
\hline A4 $U^{\min }$ & 0.1117 & & 0.0341 & 0.1586 & 0.0098 \\
\hline A5 $U^{\max }$ & - & 0.6482 & - & - & - \\
\hline A5 $U^{\min }$ & 0.0779 & & 0.0392 & 0.1269 & 0.0092 \\
\hline A6 $U^{\max }$ & - & 0.6482 & - & - & - \\
\hline A6 $U^{\text {min }}$ & 0.1197 & & 0.0360 & 0.1220 & 0.0092 \\
\hline A7 $U^{\max }$ & - & 0.3327 & - & - & - \\
\hline $\mathrm{A} 7 U^{\min }$ & 0.0745 & & 0.0423 & 0.1133 & 0.0086 \\
\hline A $8 U^{\max }$ & - & 0.6482 & - & - & - \\
\hline A8 $U^{\min }$ & 0.1155 & & 0.0410 & 0.1175 & 0.0092 \\
\hline A9 $U^{\max }$ & - & 0.1705 & - & - & - \\
\hline A9 $U^{\min }$ & 0.0838 & & 0.0417 & 0.0906 & 0.0086 \\
\hline $\mathrm{A} 10 U^{\max }$ & - & 0.1705 & - & - & - \\
\hline $\mathrm{A} 10 U^{\min }$ & 0.0798 & & 0.0404 & 0.0881 & 0.0086 \\
\hline $\mathrm{A} 11 U^{\max }$ & - & 0.3327 & - & - & - \\
\hline $\mathrm{A} 11 U^{\min }$ & 0.1197 & & 0.0469 & 0.0961 & 0.0086 \\
\hline $\mathrm{A} 12 U^{\max }$ & - & 0.3327 & - & - & - \\
\hline $\mathrm{A} 12 U^{\min }$ & 0.1155 & & 0.0597 & 0.0933 & 0.0086 \\
\hline
\end{tabular}

The next step in this selection process was to calculate the magnitude of the optimal and other components using Formulas (16)-(18). Values obtained within this step are shown in Table 16. 
Table 16. Magnitude of optimal alternative and alternatives.

\begin{tabular}{ccc}
\hline & Max & Min \\
\cline { 2 - 3 } Alternative & $Q_{k}$ & $Q_{h}$ \\
& $U_{i k}$ & $U_{i h}$ \\
\hline$Q$ & 0.6482 & 0.2108 \\
\hline A1 & 0.6482 & 0.1815 \\
A2 & 0.3327 & 0.1761 \\
A3 & 0.6482 & 0.2030 \\
A4 & 0.3327 & 0.1972 \\
A5 & 0.6482 & 0.1542 \\
A6 & 0.6482 & 0.1749 \\
A7 & 0.3327 & 0.1423 \\
A8 & 0.6482 & 0.1701 \\
A9 & 0.1705 & 0.1305 \\
A10 & 0.1705 & 0.1258 \\
A11 & 0.3327 & 0.1607 \\
A12 & 0.3327 & 0.1603 \\
\hline
\end{tabular}

Multiple Criteria Ranking by Alternative Trace (MCRAT)

Matrix $F$ composed of optimal alternative components is as follows:

$$
F=\left[\begin{array}{cc}
Q_{k} & 0 \\
0 & Q_{h}
\end{array}\right]=\left[\begin{array}{cc}
0.6482 & 0 \\
0 & 0.2108
\end{array}\right]
$$

Matrix $G_{1}$ composed of A1 alternative components is as follows:

$$
G_{1}=\left[\begin{array}{cc}
U_{1 k} & 0 \\
0 & U_{1 h}
\end{array}\right]=\left[\begin{array}{cc}
0.6482 & 0 \\
0 & 0.1815
\end{array}\right]
$$

The matrix $T_{1}$ defined by the product of matrix $F$ and $G_{i}$ is:

$$
T_{1}=F \times G_{1}=\left[\begin{array}{cc}
t_{11 ; 1} & 0 \\
0 & t_{22 ; 1}
\end{array}\right]=\left[\begin{array}{cc}
0.4202 & 0 \\
0 & 0.0383
\end{array}\right]
$$

Trace of the matrix $T_{1}$ is as follows:

$$
\operatorname{tr}\left(T_{1}\right)=t_{11 ; 1}+t_{22 ; 1}=0.4202+0.0383=0.4585
$$

Table 17 represents the trace of the matrix $T_{1}, T_{2}, \ldots, T_{12}$.

Table 17. Trace of the matrix $T_{1}, T_{2}, \ldots, T_{12}$.

\begin{tabular}{ccc}
\hline Alternative & Trace & Value \\
\hline A1 & $\operatorname{tr}\left(T_{1}\right)$ & 0.45847 \\
A2 & $\operatorname{tr}\left(T_{2}\right)$ & 0.25280 \\
A3 & $\operatorname{tr}\left(T_{3}\right)$ & 0.46299 \\
A4 & $\operatorname{tr}\left(T_{4}\right)$ & 0.25725 \\
A5 & $\operatorname{tr}\left(T_{5}\right)$ & 0.45271 \\
A6 & $\operatorname{tr}\left(T_{6}\right)$ & 0.45707 \\
A7 & $\operatorname{tr}\left(T_{7}\right)$ & 0.24568 \\
A8 & $\operatorname{tr}\left(T_{8}\right)$ & 0.45605 \\
A9 & $\operatorname{tr}\left(T_{9}\right)$ & 0.13803 \\
A10 & $\operatorname{tr}\left(T_{10}\right)$ & 0.13704 \\
A11 & $\operatorname{tr}\left(T_{11}\right)$ & 0.24956 \\
A12 & $\operatorname{tr}\left(T_{12}\right)$ & 0.24947 \\
\hline
\end{tabular}


After representing the trace of the matrix $T_{1}, T_{2}, \ldots, T_{12}$, in the previous table, we can demonstrate the final step: ranking by descending order as presented in Table 18.

Table 18. Alternatives ranked according to the descending order of obtained traces.

\begin{tabular}{cc}
\hline Alternative & Rank \\
\hline A1 & 2 \\
A2 & 7 \\
A3 & 1 \\
A4 & 6 \\
A5 & 5 \\
A6 & 3 \\
A7 & 10 \\
A8 & 4 \\
A9 & 11 \\
A10 & 12 \\
A11 & 8 \\
A12 & 9 \\
\hline
\end{tabular}

Ranking the Alternatives by Perimeter Similarity (RAPS)

According to Equations (24)-(26) the following results were obtained and shown in Table 19.

Table 19. Perimeter similarity of each alternative.

\begin{tabular}{ccccc}
\hline & Max & Min & Perimeter & Perimeter Similarity \\
\cline { 2 - 5 } & $Q_{k}$ & $Q_{h}$ & $\boldsymbol{P}=Q_{k}+Q_{h}+\sqrt{Q_{k}^{2}+Q_{k}^{2}}$ & $P S_{i}=\frac{P_{i}}{P}, \forall i \in[1,2, \ldots, m]$ \\
\hline & $U_{i k}$ & $U_{i h}$ & $\boldsymbol{P}_{i}=U_{i k}+U_{i h}+\sqrt{U_{i k}^{2}+U_{i h}^{2}}$ & \\
\hline A1 & 0.6482 & 0.2108 & 1.54067 & 0.9755 \\
A2 & 0.6482 & 0.1815 & 1.50294 & 0.5746 \\
A3 & 0.3327 & 0.1761 & 0.88528 & 0.9934 \\
A4 & 0.6482 & 0.2030 & 1.53049 & 0.5950 \\
A5 & 0.3327 & 0.1972 & 0.91669 & 0.9533 \\
A6 & 0.6482 & 0.1542 & 1.46879 & 0.9700 \\
A7 & 0.6482 & 0.1749 & 1.49451 & 0.5432 \\
A8 & 0.3327 & 0.1423 & 0.83688 & 0.9661 \\
A9 & 0.6482 & 0.1701 & 1.48845 & 0.3348 \\
A10 & 0.1705 & 0.1305 & 0.51574 & 0.3299 \\
A11 & 0.1705 & 0.1258 & 0.50820 & 0.5601 \\
A12 & 0.3327 & 0.1607 & 0.86296 & 0.5597 \\
\hline
\end{tabular}

Alternatives are now ranked according to the descending order of the obtained perimeter similarities and shown in Table 20.

Table 20. Ranking of alternatives by RAPS method.

\begin{tabular}{cc}
\hline Alternative & Rank \\
\hline A1 & 2 \\
A2 & 7 \\
A3 & 1 \\
A4 & 6 \\
A5 & 5 \\
A6 & 3 \\
A7 & 10 \\
A8 & 4 \\
A9 & 11 \\
\hline
\end{tabular}


Table 20. Cont.

\begin{tabular}{cc}
\hline Alternative & Rank \\
\hline A10 & 12 \\
A11 & 8 \\
A12 & 9 \\
\hline
\end{tabular}

\section{Discussion}

In this paper, two novel MCDM methods are presented, tested and validated in a mining engineering setting. The methods, MCRAT and RAPS, use the matrix trace and perimeter similarity concepts, respectively, to obtain a ranking of alternatives. Results obtained were compared with results obtained by seven well-known and widely used MCDM methods by means of rank correlation: TAOV, ARAS, SAW, TOPSIS, COPRAS, VIKOR, WASPAS and ELECTRE.

Results obtained by the MCRAT method show the best correlation with TOPSIS (0.97), and the worst with VIKOR (0.79), while the RAPS method shows the best correlation with TOPSIS and COPRAS (0.96) and the worst with VIKOR (0.80). In addition, the mutual rank correlation coefficient between the two methods is very high (0.98).

By observing the obtained order of alternatives, it can be noted that the first ranked alternatives coincide for all methods observed, apart from the ARAS method. The same is valid for the second ranked alternative, i.e., alternative no. 9 is second place for all methods, apart from ARAS (first place). Furthermore, there are no major discrepancies in ranking orders, meaning that the average order of alternatives is preserved throughout the results of all methods.

In another example, some other MCDM methods are added, and a calculation of correlation is performed. The novel methods have the highest correlation with VIKOR and GRA (MinMax). MCRAT and RAPS have a negative correlation with GRA(T), as do other methods in this example. This indicates the capability of the proposed methods to rank alternatives in a very successful way. The mutual rank correlation between the two novel methods in this example is 1.

An evaluation of both novel methods by means of evaluation criteria proposed by Saaty and Ergu [34] is provided in order to help the reader determine the potential scope of both methods. Table 21 summarizes the preliminary evaluation of MCRAT and RAPS according to a list of criteria developed by Saaty and Ergu. The evaluation is deemed preliminary because in cases where an evaluation criterion is related to certain aspects of the procedures for both methods (such as generalization to ranking of intangibles or rank preservation) the potential of both methods is designed to be without limitations but remains to be tested.

Table 21. Evaluation of MCRAT and RAPS methods.

\begin{tabular}{ccc}
\hline Criterion & MCRAT & RAPS \\
\hline Simplicity & High & High \\
Comprehensive structure: breadth and depth & Medium & Medium \\
Comprehensive structure consisting of merit substructures & High & High \\
Logical procedure & High & High \\
Justification & High & High \\
Measurement scale & High & High \\
Synthesis of judgements & Medium & Medium \\
Ranking of tangibles & High & High \\
Generalization of ranking & High & High \\
Rank preservation & High & High \\
Sensitivity analysis & Medium & Medium \\
\hline
\end{tabular}


Table 21. Cont.

\begin{tabular}{ccc}
\hline Criterion & MCRAT & RAPS \\
\hline Validation of decision problems & High & High \\
Generalizability to dependence & High & High \\
Applicability to conflict resolution & Medium & Medium \\
Trustworthiness and validity of the approach & Medium & Medium \\
\hline
\end{tabular}

In this analysis, the authors' recommendation on rating of the methods system was used as well.

It can be concluded that, despite having different mathematical interpretations, since both methods rely on the same initial presumptions and inception procedures, the validation results are the same. This is a reasonable result since the validation criteria suggested by Saaty and Ergu deal with general notions and settings of a MCDM method.

Based on the comparison of obtained ranks with the other MCDM methods for a mining engineering problem, and the evaluation of both methods, both are suitable for use in an MCDM environment.

For a hypothetical dacite mine with an annual capacity of 300,000.00 tons of different fractions of dacite, the authors calculated 12 different blasting patterns, because drilling and blasting are methods which are used for separating dacite from Rock mass. Results of each pattern are shown as five criteria to evaluate alternatives and select the optimal one. Criteria that the authors used as the most important for an adequate blasting process were powder factor, fragmentation, fly rock, air shock and cost of each pattern applied. Each criterion presented some important aspect of the mining process that should be paid maximum attention. Those aspects imply production, safety issues and economic effects.

\section{Conclusions}

This research presented two novel methods of MCDM and has shown how to successfully apply those methods to mining engineering problems. Decision making in blasting design is difficult because experts must consider many attributes that undoubtedly have an influence on the evaluation of blasting design. Safety is vital for this operation because if it is not conducted properly, it may cause irreparable damage by endangering employees, equipment or the environment.

In a previous part of this paper, two novel methods (MCRAT and RAPS) were applied to select the optimal pattern by considering five criteria important for the mining process. In each selecting process alternative, 3 (A3) has been optimal solution in this particular example. The alternative with a hole diameter of $76 \mathrm{~mm}$, hole length of $16.3 \mathrm{~m}$, stemming of $3 \mathrm{~m}$, burden of $3 \mathrm{~m}$, spacing of $3 \mathrm{~m}$ and subdrill of $0.76 \mathrm{~m}$ has been selected as optimal for dacite blasting with geometry and conditions described in this paper.

Further research can be related by increasing the uncertainty of input data. The model is not closed and can be extended with the application of fuzzy or interval numbers directly in calculations. Including that volatile environment of input data helps a mining company to develop a reliable and realistic mine production plan. In addition, the application of stochastic differential equations can be applied to describe the future change of some criteria such as costs through the time period. In that way, we can create a dynamic model burdened with some uncertainties.

Author Contributions: Conceptualization, K.U. and Z.G.; methodology, K.U. and I.M.; validation, I.M. and Z.G.; formal analysis, M.G.; writing original draft preparation, K.U.; supervision, Č.B. All authors have read and agreed to the published version of the manuscript.

Funding: This research received no external funding.

Institutional Review Board Statement: Not applicable.

Informed Consent Statement: Not applicable. 


\section{Data Availability Statement: Not applicable.}

Conflicts of Interest: The authors declare no conflict of interest.

Glossary
Acronyms
MCDM
MCRAT
RAPS
ELECTRE
AHP
TOPSIS
PROMETHEE
MOORA
WASPAS
TAOV
ARAS
SAW
COPRAS
VIKOR
GRA
CP

Full Names Multiple Criteria Decision Making Multiple Criteria Ranking by Alternative Trace Ranking Alternatives by Perimeter Similarity Elimination Et Choice Translating Reality Analytic Hierarchy Process Technique for Order of Preference by Similarity to Ideal Solution Preference Ranking Organization Method for Enrichment of Evaluations Multi-Objective Optimization by Ratio Analysis Weighted Aggregated Sum Product Assessment Total Area Based on Orthogonal Vectors Additive Ratio Assessment Simple Additive Weighting Complex Proportional Assessment Visekriterijumska Optimizacija i Kompromisno Resenje Grey Relational Analysis Compromise Programming

\section{References}

1. Gandibleux, X. (Ed.) Multiple Criteria Optimization: State of the Art Annotated Bibliographic Surveys; Kluwer Academic Publishers: Amsterdan, The Netherlands, 2006.

2. Sen, P.; Yang, J.B. Multiple Criteria Decision Support in Engineering Design; Springer: London, UK, 1998.

3. Greco, S.; Figueira, J.; Ehrgott, M. Multiple Criteria Decision Analysis, 2nd ed.; Springer: New York, NY, USA, 2016.

4. Sitorus, F.; Cilliers, J.J.; Brito-Parada, P.R. Multi-criteria decision making for the choice problem in mining and mineral processing: Applications and trends. Expert Syst. Appl. 2019, 121, 393-417. [CrossRef]

5. Munier, N.; Hontoria, E.; Jiménez-Sáez, F. Strategic Approach in Multi-Criteria Decision Making; Springer: Cham, Switzerland, 2019.

6. Roy, B. The outranking approach and the foundations of ELECTRE methods. In Readings in Multiple Criteria Decision Aid; Springer: Berlin/Heidelberg, Germany, 1990; pp. 155-183.

7. Saaty, T.L. The Analytic Hierarchy Process; McGraw-Hill: New York, NY, USA, 1980.

8. Hwang, C.L.; Yoon, K. Methods for Multiple Attribute Decision Making. In Multiple Attribute Decision Making. Lecture Notes in Economics and Mathematical Systems; Springer: Berlin/Heidelberg, Germany, 1981; Volume 186, pp. 58-191.

9. Brans, J.P.; Vincke, P.; Mareschal, B. How to select and how to rank projects: The PROMETHEE method. Eur. J. Oper. Res. 1986, 24, 228-238. [CrossRef]

10. Tzeng, G.H.; Huang, J.J. Multiple Attribute Decision Making: Methods and Applications; CRC Press: Boca Raton, FL, USA, 2011.

11. Figueira, J.; Greco, S. Trends in Multiple Criteria Decision Analysis, 1st ed.; Springer: Boston, MA, USA, 2010.

12. Ishizaka, A.; Nemery, P. Multi-Criteria Decision Analysis: Methods and Software; John Wiley \& Sons: Hoboken, NJ, USA, 2013; ISBN 978-1-118-64491-1.

13. Doumpos, M.; Figueira, J.R.; Greco, S.; Zopounidis, C. (Eds.) New Perspectives in Multiple Criteria Decision Making: Innovative Applications and Case Studies; Springer: London, UK, 2019.

14. Zavadskas, K.E.; Antucheviciene, J.; Adeli, H.; Turskis, Z. Hybrid multiple criteria decision making methods: A review of applications in engineering. Sci. Iran. 2016, 23, 1-20.

15. Wang, P.; Zhu, Z.; Wang, Y. A novel hybrid MCDM model combining the SAW, TOPSIS and GRA methods based on experimental design. Inf. Sci. 2016, 345, 27-45. [CrossRef]

16. Alinezhad, A.; Khalili, J. New Methods and Applications in Multiple Attribute Decision Making (MADM), 1st ed.; Springer: Cham, Switzerland, 2019; p. 236.

17. Brauers, W.K.; Zavadskas, E.K. The MOORA method and its application to privatization in a transition economy. Control Cybern. 2006, 35, 445-469.

18. Zavadskas, E.K.; Turskis, Z.; Antucheviciene, J.; Zakarevicius, A. Optimization of weighted aggregated sum product assessment. Elektron. Elektrotechnika 2012, 122, 3-6. [CrossRef]

19. Kraujalienè, L. Comparative analysis of multicriteria decision-making methods evaluating the efficiency of technology transfer. Bus. Manag. Educ. 2019, 17, 72-93. [CrossRef]

20. Velasquez, M.; Hester, P.T. An analysis of multi-criteria decision making methods. Int. J. Oper. Res. 2013, 10, 56-66. 
21. Hodgett, R.E. Comparison of multi-criteria decision-making methods for equipment selection. Int. J. Adv. Manuf. Technol. 2016, 85, 1145-1157. [CrossRef]

22. Siksnelyte-Butkiene, I.; Zavadskas, E.K.; Streimikiene, D. Multi-criteria decision-making (MCDM) for the assessment of renewable energy technologies in a household: A review. Energies 2020, 13, 1164. [CrossRef]

23. Siksnelyte, I.; Zavadskas, E.K.; Streimikiene, D.; Sharma, D. An overview of multi-criteria decision-making methods in dealing with sustainable energy development issues. Energies 2018, 11, 2754. [CrossRef]

24. Hajiagha, S.H.R.; Mahdiraji, H.A.; Hashemi, S.S. Total area based on orthogonal vectors (Taov) as a novel method of multi-criteria decision aid. Technol. Econ. Dev. Econ. 2018, 24, 1679-1694. [CrossRef]

25. Zavadskas, E.K.; Turskis, Z. A new additive ratio assessment (ARAS) method in multicriteria decision-making. Technol. Econ. Dev. Econ. 2010, 16, 159-172. [CrossRef]

26. Liu, N.; Xu, Z. An overview of ARAS method: Theory development, application extension, and future challenge. Int. J. Intell. Syst. 2021, 36, 3524-3565. [CrossRef]

27. Kuo, Y.; Yang, T.; Huang, G.W. The use of grey relational analysis in solving multiple attribute decision-making problems. Comput. Ind. Eng. 2008, 55, 80-93.

28. Mahmoudi, A.; Javed, S.A. Grey multiple criteria decision making methods: A literature review. ICSES Trans. Neural Fuzzy Comput. 2019, 2, 1-13.

29. Sitorus, F. The Development of Multiple Criteria Decision Making Methods with Applications to the Selection Problem in Mining and Mineral Processing. Ph.D. Thesis, Department of Earth Science and Engineering, Imperial College, London, UK, 2020.

30. Zavadskas, E.K.; Turskis, Z.; Vilutiene, T. Multiple criteria analysis of foundation instalment alternatives by applying Additive Ratio Assessment (ARAS) method. Arch. Civil Mech. Eng. 2010, 10, 123-141. [CrossRef]

31. Churchman, C.W.; Ackoff, R.L. An approximate measure of value. J. Oper. Res. Soc. Am. 1954, 2, 172-187. [CrossRef]

32. Zavadskas, E.K.; Kaklauskas, A.; Peldschus, F.; Turskis, Z. Multi-attribute assessment of road design solutions by using the COPRAS method. Balt. J. Road Bridge Eng. 2007, 2, 195-203.

33. Opricovic, S.; Tzeng, G.H. Multicriteria planning of post-earthquake sustainable reconstruction. Comput. Aided Civil Infrastruct. Eng. 2002, 17, 211-220. [CrossRef]

34. Saaty, T.L.; Ergu, D. When is a decision-making method trustworthy? Criteria for evaluating multi-criteria decision-making methods. Int. J. Inf. Technol. Decis. Mak. 2015, 14, 1171-1187. [CrossRef]

35. Purtić, N. Bušenje i Miniranje; Faculty of Mining and Geology: Belgrade, Serbia, 1991.

36. Monjezi, M.; Dehghani, H.; Singh, T.N.; Sayadi, A.R.; Gholinejad, A. Application of TOPSIS method for selecting the most appropriate blast design. Arab. J. Geosci. 2012, 5, 95-101. [CrossRef]

37. Javad Rahimdel, M.; Aryafar, A.; Tavakkoli, E. Selection of the most proper drilling and blasting pattern by using MADM methods (A case study: Sangan Iron Ore Mine, Iran). Min. Geol. Pet. Bull. 2020, 35, 97-108.

38. Sight, S.P.; Singh, R.; Narendrula, D. Duffy Influence of blasted muck on the productivity of the loading equipment. In Proceedings of the 3rd EFEE Conference on Explosives and Blasting, Brighton, UK, 14-16 September 2005; pp. 347-353.

39. Chakraborty, A.K.; Guha, P.; Chattopadhyay, B.; Pal, S.; Das, J. A fusion Neural Network for estimation of blasting vibration. In Neural Information Processing; ICONIP 2004. Lecture Notes in Computer Science; Springer: Berlin/Heidelberg, Germany, 2004; Volume 3316, pp. 1008-1013.

40. Fişne, A.; Kuzu, C.; Hüdaverdi, T. Prediction of environmental impacts of quarry blasting operation using fuzzy logic. Environ. Monit. Assess. 2011, 174, 461-470. [CrossRef] [PubMed]

41. Ghasemi, E.; Amini, H.; Ataei, M.; Khalokakaei, R. Application of artificial intelligence techniques for predicting the flyrock distance caused by blasting operation. Arab. J. Geosci. 2012, 7, 193-202. [CrossRef]

42. Shannon, C.E. A mathematical theory of communication. Bell Syst. Tech. J. 1948, 27, 379-423. [CrossRef]

43. Stanujkić, D.; Djordjevic, B.; Djordjevic, M. Comparative analysis of some prominent MCDM methods: A case of ranking Serbian banks. Serb. J. Manag. 2013, 8, 213-241. [CrossRef] 